\title{
Possibility of compiling results of individual trials under a single model
}

\author{
Yunus Babur \\ Soil Department, Ege University Agricultural Faculty, Izmir, Turkey \\ Email address: \\ yunusbabur@ymail.com
}

To cite this article:

Yunus Babur. Possibility of Compiling Results of Individual Trials under a Single Model. Science Journal of Applied Mathematics and Statistics. Vol. 2, No. 4, 2014, pp. 85-90. doi: 10.11648/j.sjams.20140204.13

\begin{abstract}
The purpose of this work is to compile individual trials conducted at various locations and times in order to build and optimize a theoretical factorial model. A factorial plan is formed using planting time, plant density, nitrogen, phosphor and irrigation water data collected from trials conducted at Nazilli Cotton Research Station in 1966, 1967, 1971 and 1972. Using infinitesimal calculus theoretical combinations were formed, and individual and final $\mathrm{R}$ values were calculated. This was done by equalizing the different individual $\mathrm{R}$ values and levels belonging to independent variables. 1 . Where the level numbers of the factors are non-recurrent (without frequency) and unequal; a) The level number of the factor with the largest level number should be accepted as the common level number. b) The individual (R) values total of the factor in question should be accepted as the final limit. c) The common individual (R) values total of the factor in question should be slightly lower than the final limit value. d) Individual (R) values calculated for each factor by finite infinitesimal calculus should be smaller than the largest individual (R) value of the factor in question. e) Finite infinitesimal calculus calculation should be started from the factor with the smallest level number. $\mathrm{f}$ ) The largest valued total calculated on the factor in question and meeting the conditions in question (equalized R values totals and level numbers) should be accepted as the common total. 2. In case the level numbers of the factors consist of recurrent (with frequency) and non-recurrent (without frequency) groups, the calculations should be based on the group with the largest frequency. The operations defined under item 1 above shall also be applicable here. 3. In case the level numbers of the factors are non-recurrent (without frequency) and equal, the operations defined under item 1 above shall also be applicable here. The relative effects of the factors on the maximum yield level are given below: $25.224 \%$ for planting time, $17.2245 \%$ for plant density, $25.904 \%$ for nitrogen, $13.904 \%$ for phosphor, and $17.90 \%$ for water. Here, five square squares of $5 \times 5$ are formed and 125 combinations are derived. Maximization was done by putting the individual $\mathrm{R}$ values with the largest final $\mathrm{R}$ value among the 125 combination in place in the formula $R=-0.6080+R_{E}+R_{B}+R_{N}+R_{P}+R_{S}$, and maximum $\mathrm{R}$ value was calculated as $R_{\max }=752.110 \mathrm{~kg} / \mathrm{dec}$ are
\end{abstract}

Keywords: Trial, Series, Factor, Factorial, Optimization

\section{Introduction}

Planning of the trials has significant importance for obtaining multi-factor models with minimum error margin and maximum numerical data. Two methods are employed in organization of multi-factor trials. These are classic and factorial plans.

Classic method is widely used in applications. On the other hand, factorial method is generally shorter and always more sensitive. Where the dependent variable $\mathrm{R}$ is a function of independent variables $\mathrm{X}, \mathrm{Y}$ and $\mathrm{Z}$, classic method allows one of the independent variables to vary in its own range, while keeping the other variables fixed. If the mathematical relations between the independent variables are simple, this may, for example, explain the function between $\mathrm{R}$ and $\mathrm{X}$. Then, $\mathrm{Y}$ is allowed to vary while the other variables are held fixed, thus deriving a separate $R_{y}$ function, and so on, and so forth. In fact, the classic multi-factor method consists of a series of factorial trials. This limited classic approach lets us reach simple functions as follows:

$$
\begin{aligned}
& \mathrm{R}=\mathrm{A} Y^{n}+\mathrm{B} X^{m} \\
& \mathrm{R}=\mathrm{A} Y^{n} X^{m} \\
& \mathrm{R}=\mathrm{AYB}{ }^{\mathrm{CX}}
\end{aligned}
$$

As well as high functions as below; 


$$
\begin{gathered}
R=A X \sin \frac{B Y}{X} \\
\mathrm{R}=\mathrm{A}+B X^{m} Y^{n}+\mathrm{C} X^{p} Y^{q}
\end{gathered}
$$

The classic model has no balance; in other words the levels of the variables are not equal. For example, while Y has ten levels, $\mathrm{X}$ may have three levels.

The factorial plan, on the other hand, has only two types of general function and balance. Namely, the levels of the $\mathrm{X}, \mathrm{Y}$ and $\mathrm{Z}$ factors are equal. For example, if $\mathrm{X}$ has two levels, then $\mathrm{Y}$ and $\mathrm{Z}$ also each have to have two levels. In addition, which type will be used should be determined before starting the operations.

The first type is an aggregation type, and formulates as;

$$
\mathrm{R}=f_{1}(\mathrm{x})+f_{2}(\mathrm{Y})+f_{3}(\mathrm{Z})
$$

This non-interaction type is widely used in engineering and physical sciences.

The second type is a product (interactive) type, and formulates as;

$$
\mathrm{R}=f_{1}(\mathrm{x}) \cdot f_{2}(\mathrm{Y}) \cdot f_{3}(\mathrm{Z})
$$

This type has a very large range of use.

There, $f_{1}(\mathrm{x}), f_{2}(\mathrm{Y})$ and.$f_{3}(\mathrm{Z})$ are functions of any level.

As an example, the combinations of a balanced factorial trial plan including factors $\mathrm{N}$ and $\mathrm{P}$, each with two levels, and corresponding product quantities are shown below.
1. $N_{1} P_{1}$
$R_{1}$
$\mathrm{R}_{2}$
3. $\mathrm{N}_{2} \mathrm{P}_{1} \quad \mathrm{R}_{3}$
2. $N_{1} \mathrm{P}_{2}$
4. $\mathrm{N}_{2} \mathrm{P}_{2} \quad \mathrm{R}$

Here, the number of combinations is $2 \times 2=4$.

Using the aggregate type, the $R_{1}$ yield corresponding to the first combination of $N_{1}$ level is formulated as follows;

$$
R_{1}=f_{1}\left(N_{1}\right)+f_{2}\left(P_{1}\right)
$$

And $\mathrm{R}_{2}$ yield corresponding to the second combination of $\mathrm{N}_{1}$ level is formulated as follows;

$$
R_{2}=f_{1}\left(N_{1}\right)+f_{2}\left(P_{2}\right)
$$

When we formulate two aggregate type functions for each of $\mathrm{N}_{1}$ and $\mathrm{N}_{2}$ levels, and add these together we obtain the following relations;

$$
\begin{aligned}
& \sum R_{N 1}=2 f_{1}\left(N_{1}\right)+f_{2}\left(P_{1}\right)+f_{2}\left(P_{2}\right) \\
& \sum R_{N 2}=2 f_{1}\left(N_{2}\right)+f_{2}\left(P_{1}\right)+f_{2}\left(P_{2}\right)
\end{aligned}
$$

Please note, in these two equations the totals of the terms from $f_{2}\left(\mathrm{P}_{1}\right)$ to $f_{2}\left(\mathrm{P}_{2}\right)$ are equal to each other. These are accepted as constants. When we solve these two equations for we obtain;

$$
\begin{aligned}
& f_{1}\left(N_{1}\right)=\frac{\sum R_{N_{1}}}{2}-\operatorname{constant}\left(D^{\prime}\right) \\
& f_{1}\left(N_{2}\right)=\frac{\sum R_{N_{2}}}{2}-\operatorname{constant}\left(D^{\prime}\right)
\end{aligned}
$$

When we do the same mathematical operations for factor $\mathrm{P}$ we obtain the following relations;

$$
\begin{aligned}
& \sum R_{P_{1}}=2 f_{2}\left(P_{1}\right)+f_{1}\left(N_{1}\right)+f_{1}\left(N_{2}\right) \\
& \sum R_{P_{2}}=2 f_{2}\left(P_{2}\right)+f_{1}\left(N_{1}\right)+f_{1}\left(N_{2}\right)
\end{aligned}
$$

and,

$$
\begin{gathered}
f_{2}\left(P_{1}\right)=\frac{\sum R_{p_{1}}}{2}-\operatorname{constant}\left(D^{\prime \prime}\right) \\
f_{2}\left(P_{2}\right)=\frac{\sum R_{p_{2}}}{2}-\operatorname{constant}\left(D^{\prime \prime}\right)
\end{gathered}
$$

Based on these we can conclude:

1. Average values are calculated for dependent variable (product quantity) corresponding to two levels of each of independent variables $\mathrm{N}$ and $\mathrm{P}$.

2. The effect of the variable $\mathbf{P}$ factor on the dependent variable is the same for all level of $\mathrm{N}$. In other works, it is expressed as $f_{2}\left(P_{1}\right)+f_{2}\left(P_{2}\right)$

3. The dependent variable is changed under the sole effect of $\mathrm{N}$.

All these results are also applicable for other variables. The analysis of the functional equations formed by each of independent variables $\mathrm{N}$ and $\mathrm{P}$ with the dependent variable $\mathrm{R}$ is done by drawing the graphs for value pairs,

$$
\left(N_{1}, \frac{\sum R_{N_{1}}}{2}\right),\left(N_{2}, \frac{\sum R_{N_{2}}}{2}\right),\left(P_{1}, \frac{\sum R_{P_{1}}}{2}\right),\left(P_{2}, \frac{\sum R_{P_{2}}}{2}\right)
$$

or by applying the least squares method.

Based on the functional equations

$$
\begin{aligned}
& f_{1}\left(N_{1}\right)=\frac{\sum R_{N_{1}}}{2}-D^{\prime}, f_{1}\left(N_{2}\right)=\frac{\sum R_{N_{2}}}{2}-D^{\prime} \\
& f_{2}\left(P_{1}\right)=\frac{\sum R_{P_{1}}}{2}-D^{\prime \prime}, f_{2}\left(P_{2}\right)=\frac{\sum R_{P_{2}}}{2}-D^{\prime \prime}
\end{aligned}
$$

And the graphs drawn from these it is understood that the following relation can be derived;

$$
R_{N}=D^{\prime}+f_{1}(N), R_{P}=D^{\prime \prime}+f_{2}(P)
$$

When we solve these three functional equations for $f_{1}(N), f_{2}(P)$ and put them in place on the general equation we obtain the following equation;

$$
\mathrm{R}=\mathrm{D}+R_{N}+R_{P}
$$

Then, we take the logarithm of both sides, and repeat the same operations to derive the general product function. Here, an aggregate type and balanced method capable of producing a multi-factor model is developed based on the results of the unplanned trials in order to derive multi-factor models. [1]

Here, combinations are produced using the converted coordinates derived from finite infinitesimal calculus $\{(\mathrm{x}+\Delta \mathrm{x}),(f(\mathrm{x}+\Delta \mathrm{x}))\}$, and individual and final $\mathrm{R}$ values were calculated. This is done by equalizing different individual $\mathrm{R}$ value and level number totals of different independent variables:

1. Where the level numbers of the factors are 
onrecurrent (without frequency) and unequal,

a) The level number of the factor with the largest level number should be accepted as the common level number.b) The individual $(\mathrm{R})$ values total of the factor in question should be accepted as the final limit.

c) The common individual $(R)$ values total of the factor in question should be slightly lower than the final limit value.

d) Individual ( $R$ ) values calculated for each factor by finite infinitesimal calculus should be smaller than the largest individual $(\mathrm{R})$ value of the factor in question.

e) Finite infinitesimal calculus calculation should be started from the factor with the smallest level number.

f) The largest valued total calculated on the factor in question and meeting the conditions in question (equalized) $R$ values totals and level numbers) should be accepted as the common total.

2. In case the level numbers of the factors consist of recurrent (with frequency) and non-recurrent (without frequency) groups, the calculations should be based on the group with the largest frequency. The operations defined under item 1 above shall also be applicable here.

3. In case the level numbers of the factors are non-recurrent (without frequency) and equal, the operations defined under item 1 above shall also be applicable here.

\section{Material and Method}

\subsection{Material}

Trials on plant density, interval and distance, chemical fertilizers, planting time and irrigation water were conducted at Nazilli Cotton Research Station in 1966, 1967, 1971 and 1972. Individual trial results (original and standard observation values) are given below.

The Observed and Standard Values for Planting Time

Table 1. The Observed and Standard Values for Planting Time January $1^{\text {st }}$ is accepted as the beginning date in calculation of planting time.

\begin{tabular}{cccc}
\hline $\begin{array}{c}\text { Planting Time (E) } \\
\text { (Day) }\end{array}$ & $\begin{array}{c}\text { Planting Time (E) } \\
\text { (Standard) }\end{array}$ & $\begin{array}{c}\text { RE } \\
\text { (kg/decare) }\end{array}$ & $\begin{array}{c}\text { RE } \\
\text { (Standard) }\end{array}$ \\
\hline 110 & 0.3762 & 384 & 0.2486 \\
120 & 0.4104 & 461 & 0.2984 \\
130 & 0.4446 & 422.5 & 0.2735 \\
140 & 0.4788 & 324 & 0.2098 \\
150 & 0.5130 & 306.5 & 0.1984 \\
\hline
\end{tabular}

Table 2. The Observed and Standard Values for Plant Density

\begin{tabular}{cccc}
\hline $\begin{array}{c}\text { Plant Density (B) } \\
\text { (pieces/decare) }\end{array}$ & $\begin{array}{c}\text { Plant Density (B) } \\
\text { (Standard) }\end{array}$ & $\begin{array}{c}\boldsymbol{R}_{\boldsymbol{B}} \\
\text { (kg/decare) }\end{array}$ & $\begin{array}{c}\boldsymbol{R}_{\boldsymbol{B}} \\
\text { (Standard) }\end{array}$ \\
\hline 3336 & 0.2467 & 181.500 & 0.1175 \\
3443 & 0.2346 & 189.600 & 0.1227 \\
4003 & 0.2960 & 235.000 & 0.1521 \\
4456 & 0.3296 & 222.000 & 0.1437 \\
4587 & 0.3392 & 199.400 & 0.1291 \\
5013 & 0.3708 & 289.000 & 0.1871 \\
5511 & 0.4076 & 354.727 & 0.2296 \\
6886 & 0.5093 & 273.428 & 0.1770 \\
\hline
\end{tabular}

Table 3. The Observed and Standard Values for Nitrogen Element

\begin{tabular}{cccc}
\hline $\begin{array}{c}\text { Nitrogen (N) } \\
\text { (kg/decare) }\end{array}$ & $\begin{array}{c}\text { Nitrogen (N) } \\
\text { (Standard) }\end{array}$ & $\begin{array}{c}\boldsymbol{R}_{\boldsymbol{N}} \\
\text { (kg/decare) }\end{array}$ & $\begin{array}{c}\boldsymbol{R}_{\boldsymbol{N}} \\
\text { (Standard) }\end{array}$ \\
\hline 0 & 0 & 298 & 0.1929 \\
4 & 0.1826 & 365 & 0.2363 \\
8 & 0.351 & 390 & 0.2525 \\
12 & 0.5477 & 410 & 0.2634 \\
16 & 0.7307 & 439 & 0.2842 \\
\hline
\end{tabular}

Table 4. The Observed and Standard Values for Phosphor Element

\begin{tabular}{cccc}
\hline $\begin{array}{c}\text { Phosphor (P) } \\
\text { (kg/decare) }\end{array}$ & $\begin{array}{c}\text { Phosphor (P) } \\
\text { (Standard) }\end{array}$ & $\begin{array}{c}\boldsymbol{R}_{\boldsymbol{P}} \\
\text { (kg/decare) }\end{array}$ & $\begin{array}{c}\boldsymbol{R}_{\boldsymbol{P}} \\
\text { (Standard) }\end{array}$ \\
\hline 0 & 0 & 223.4 & 0.1446 \\
6 & 0.4472 & 233.0 & 0.1508 \\
12 & 0.8944 & 235.0 & 0.1521 \\
\hline
\end{tabular}

Table 5. The Observed and Standard Values for Irrigation Water

\begin{tabular}{cccc}
\hline $\begin{array}{c}\text { Water (S) } \\
\text { (tonne/decare) }\end{array}$ & $\begin{array}{c}\text { Water }(\mathbf{S}) \\
\text { (Standard) }\end{array}$ & $\begin{array}{c}\boldsymbol{R}_{\boldsymbol{S}} \\
\text { (kg/decare) }\end{array}$ & $\begin{array}{c}\boldsymbol{R}_{\boldsymbol{S}} \\
\text { (Standard) }\end{array}$ \\
\hline 0 & 0 & 115.1667 & 0,0746 \\
100 & 0.1962 & 169.000 & 0,1094 \\
200 & 0.3904 & 213.833 & 0,1384 \\
300 & 0.5855 & 280,6670 & 0,1817 \\
350 & 0.6831 & 301,1670 & 0,1930 \\
\hline
\end{tabular}

Standardization operations

stx $=\frac{X}{\sqrt{\Sigma x^{2}}}, \quad X=E, B, P, S ;$ sty $=\frac{y}{\sqrt{\Sigma y^{2}}}, y=R_{E}, R_{B}, R_{N}, R_{P}, R_{S}$

$\Sigma y^{2}=\Sigma R_{E}^{2}+\Sigma R_{B}^{2}+\Sigma R_{N}^{2}+\Sigma R_{P}^{2}+\Sigma R_{S}^{2}$

\subsection{Method}

Based on the data from Item 4.1, regression equations and relevant values are calculated for the variables E, B, N, $\mathrm{P}$ and $\mathrm{S}$, using the least squares method.

$$
\begin{aligned}
& R_{E}=-1.4314+8.2009 X-9.8443 X^{2} \\
& R_{B}=-0.1969+1.7097 X-1.8743 X^{2} \\
& R_{N}=0.1964+0.1981 X-0.1125 X^{2} \\
& R_{P}=0.1446+0.0193 X-0.0122 X^{2} \\
& R s=0.0750+0.1614 X-0.0247 X^{2}
\end{aligned}
$$

Now, let's assume that the conditions in questions are the common conditions without combinations, or in other words conditions where only the individual trial results are known. In this case, we would have to generate new combinations and know the final $\mathrm{R}$ values and individual $\mathrm{R}$ values for these combinations [1, 4, 5]. Even in absence of $\mathrm{R}$ values of the combinations and the individual values of $R_{E}, R_{B}, R_{N}, R_{P}$ and $R_{S}$, we know the existence of following relations

$$
\begin{gathered}
\Sigma R=\Sigma R_{E}=\Sigma R_{B}=\Sigma R_{N}=\Sigma R_{P}=\Sigma R_{S} \\
\mathrm{D}=\frac{\Sigma R-\Sigma R_{E}-\Sigma R_{B}-\Sigma R_{N}-\Sigma R_{P}-\Sigma R_{S}}{n}
\end{gathered}
$$


$\mathrm{n}=$ Total number of combinations.

Therefore, using these relations, it is possible to solve the problem. Combinations and their final $\mathrm{R}$ values and individual $\mathrm{R}$ values are obtained by the following stages.

1. The differences in question between individual $\mathrm{R}$ value totals and independent variable levels of the individual trials were rectified. In other words, all individual $\mathrm{R}$ value totals and independent variable levels were equalized. The equalized. level number applicable for all individual trials should be at a suitable point between the minimum and maximum level numbers. To this end, following operations were carried out.

For factor E:

$\mathrm{R}_{\mathrm{E}}=-1.4314+8.2009 \mathrm{X}-9.8443 \mathrm{X}^{2}$

$\Sigma R_{E}=0.7600$ and the independent variable $\mathrm{E}$ has five levels. In result of the conducted tests the individual $\mathrm{R}$ values total $=0.7600$ and a level number of five accommodates all regression functions. Therefore;

$\mathrm{Y}=f(\mathrm{X})=\mathrm{R}_{\mathrm{E}}=-1.4314+8.2009 \mathrm{X}-9.8443 \mathrm{X}^{2}$

Where $\mathrm{X}_{5}=0.4104$ then $f(0.4104)=0.2762$

Here, $f\left(\mathrm{X}_{5}\right)=f(0.4104)$ expresses the maximum value. Where $X_{1}=\mathrm{X}$

Then $f(X)=-1.4314+8.2009 X-9.8443 X^{2}$

$\Delta Y=8.2009 \Delta X-19.6886 X \Delta X-9.8443 \Delta X^{2}$

Where $\Delta X=0.01$ then $\Delta Y=0.0810-0.1969 X$

$\mathrm{Y}_{2}=\mathrm{Y}_{1}+\Delta Y=1.3504+8.004 \mathrm{X}-9.8443 \mathrm{X}^{2}$

$\Delta Y=8.004 \Delta X-19.6886 X \Delta X-9.8443 \Delta X^{2}$

Where $\Delta \mathrm{X}=0.01$ then $\Delta \mathrm{Y}=0.0790-0.1969 \mathrm{X}$

$\mathrm{Y}_{3}=\mathrm{Y}_{2}+\Delta Y=-1.2714+7.8071 \mathrm{X}-9.8443 \mathrm{X}^{2}$

$\Delta Y=7.8071 \Delta X-19.6886 X \Delta X-9.8443 \Delta X^{2}$

Where $\Delta \mathrm{X}=0.01$ then $\Delta \mathrm{Y}=0.00771-0.1969 \mathrm{X}$

$\mathrm{Y}_{4}=\mathrm{Y}_{3}+\Delta Y=-1.1943+7.6102 \mathrm{X}-9.8443 \mathrm{X}^{2}$

Therefore,

$X_{1}+X_{2}+X_{3}+X_{4}=-5.2475+31.6222 X-39.3772 X^{2}$

On the other hand;

$0.7600-02762=0.4838$

$Y_{1}+\mathrm{Y} 2+\mathrm{Y} 3+\mathrm{Y} 4=-5.2475+31.6222 \mathrm{X}-39.3772 \mathrm{X} 2=0.483$

Among the roots of this equation $X_{1}=0.2762$,

$\mathrm{X}_{2}=0.5268$ is chosen. Because $\mathrm{X}_{2}>\mathrm{X}_{5}$ and $f(0.2762)=0.0830$.

Therefore,

$X_{2}=X_{1}+\Delta \mathrm{X}=0.2762+0.01=0.2862 \quad[6]$

$$
f(0.2862)=0.1096
$$

And continued as,

$$
\begin{aligned}
& f(0.2962)=0.1343 \\
& f(0.3062)=0.1569
\end{aligned}
$$

Accordingly;

\begin{tabular}{cccccc}
\hline $\mathrm{X}$ & $R_{E}$ & $\mathrm{X}$ & $R_{B}$ & $\mathrm{X}$ & $R_{N}$ \\
\hline 0.2762 & 0.0830 & 0.2778 & 0.1334 & 0.7303 & 0.2811 \\
0.2862 & 0.1096 & 0.2878 & 0.1399 & 2.0725 & 0.1237 \\
0.2962 & 0.1343 & 0.2978 & 0.1460 & 2.0825 & 0.1210 \\
0.3062 & 0.1596 & 0.3078 & 0.1521 & 2.0925 & 0.1183 \\
0.4104 & 0.2762 & 0.4076 & 0.1886 & 2.1025 & 0.1159 \\
& $\Sigma R_{E}=0.7600$ & & $\Sigma R_{B}=0.7600$ & \multicolumn{2}{c}{$\Sigma R_{N}=0.7600$} \\
\hline
\end{tabular}

When we perform the same operations for the other factors;

\begin{tabular}{cccc}
\hline $\mathrm{X}$ & $\mathrm{RP}$ & $\mathrm{X}$ & $R_{S}$ \\
\hline 0.616 & 0.1518 & 0.3683 & 0.1378 \\
0.626 & 0.1519 & 0.3783 & 0.1396 \\
0.636 & 0.1520 & 0.3883 & 0.1414 \\
0.646 & 0.1522 & 0.3983 & 0.1444 \\
0.8944 & 0.1321 & 0.6831 & 0.1968 \\
& $\Sigma R_{P}=0.7600$ & & $\Sigma R_{S}=0.7600$ \\
\hline
\end{tabular}

2. At second stage, since the number of the independent variables $(\mathrm{E}, \mathrm{B}, \mathrm{N}, \mathrm{P}, \mathrm{S})$ is five and each of these has five levels, it is concluded that the independent variables in question can only and only form 125 combinations by five squares sized $5 \times 5$.

Since it is exceedingly hard to form a five level and five variable Greco-Latin squares in combination number calculation, the method defined herein is used to form 5 squares sized $5 \times 5$ to generate 125 combinations. Following steps are followed in generation of the squares.

a) To obtain the first square, for example, the levels of factors $\mathrm{N}, \mathrm{P}$ and $\mathrm{S}$ are arranged in the form below, and then

\begin{tabular}{|c|c|c|c|c|c|c|}
\hline \multicolumn{3}{|c|}{$N_{1} N_{1} N_{1} N_{1} N_{1}$} & \multicolumn{2}{|c|}{$P_{1} P_{2} P_{3} P_{4} P_{5}$} & \multicolumn{2}{|c|}{$S_{1} S_{2} S_{3} S_{4} S_{5}$} \\
\hline \multicolumn{3}{|c|}{$N_{2} N_{2} N_{2} N_{2} N_{2}$} & \multicolumn{2}{|c|}{$P_{1} P_{2} P_{3} P_{4} P_{5}$} & \multicolumn{2}{|c|}{$S_{2} S_{4} S_{1} S_{5} S_{3}$} \\
\hline \multicolumn{3}{|c|}{$N_{3} N_{3} N_{3} N_{3} N_{3}$} & \multicolumn{2}{|c|}{$P_{1} P_{2} P_{3} P_{4} P_{5}$} & \multicolumn{2}{|c|}{$S_{3} S_{1} S_{5} S_{2} S_{4}$} \\
\hline \multicolumn{3}{|c|}{$N_{4} N_{4} N_{4} N_{4} N_{4}$} & \multicolumn{2}{|c|}{$P_{1} P_{2} P_{3} P_{4} P_{5}$} & \multicolumn{2}{|c|}{$S_{4} S_{5} S_{2} S_{3} S_{1}$} \\
\hline \multicolumn{3}{|c|}{$N_{5} N_{5} N_{5} N_{5} N_{5}$} & \multicolumn{2}{|c|}{$P_{1} P_{2} P_{3} P_{4} P_{5}$} & \multicolumn{2}{|c|}{$S_{5} S_{3} S_{4} S_{1} S_{2}$} \\
\hline$E_{1}$ & $\mathrm{~B}_{1}$ & $\mathrm{~B}_{2}$ & $\mathrm{~B}_{3}$ & $\mathrm{~B}_{4}$ & $\mathrm{~B}_{5}$ & \\
\hline & $\mathrm{N}_{1} \mathrm{P}_{1} \mathrm{~S}_{1}$ & $\mathrm{~N}_{1} \mathrm{P}_{2} \mathrm{~S}_{2}$ & $\mathrm{~N}_{1} \mathrm{P}_{3} \mathrm{~S}_{3}$ & $\mathrm{~N}_{1} \mathrm{P}_{4} \mathrm{~S}_{4}$ & $\mathrm{~N}_{1} \mathrm{P}_{5} \mathrm{~S}_{5}$ & \\
\hline$E_{2}$ & $\mathrm{~N}_{2} \mathrm{P}_{1} \mathrm{~S}_{2}$ & $\mathrm{~N}_{2} \mathrm{P}_{2} \mathrm{~S}_{4}$ & $\mathrm{~N}_{2} \mathrm{P}_{3} \mathrm{~S}_{1}$ & $\mathrm{~N}_{2} \mathrm{P}_{4} \mathrm{~S}_{5}$ & $\mathrm{~N}_{2} \mathrm{P}_{5} \mathrm{~S}_{3}$ & $1-2-3-4-5$ \\
\hline$E_{3}$ & $\mathrm{~N}_{3} \mathrm{P}_{1} \mathrm{~S}_{3}$ & $\mathrm{~N}_{3} \mathrm{P}_{2} \mathrm{~S}_{1}$ & $\mathrm{~N}_{2} \mathrm{P}_{3} \mathrm{~S}_{5}$ & $\mathrm{~N}_{3} \mathrm{P}_{4} \mathrm{~S}_{3}$ & $\mathrm{~N}_{3} \mathrm{P}_{5} \mathrm{~S}_{4}$ & \\
\hline $\mathrm{E}_{4}$ & $\mathrm{~N}_{4} \mathrm{P}_{1} \mathrm{~S}_{4}$ & $\mathrm{~N}_{4} \mathrm{P}_{2} \mathrm{~S}_{5}$ & $\mathrm{~N}_{4} \mathrm{P}_{3} \mathrm{~S}_{2}$ & $\mathrm{~N}_{4} \mathrm{P}_{4} \mathrm{~S}_{3}$ & $\mathrm{~N}_{4} \mathrm{P}_{5} \mathrm{~S}_{1}$ & \\
\hline $\mathrm{E}_{5}$ & $\mathrm{~N}_{5} \mathrm{P}_{1} \mathrm{~S}_{5}$ & $\mathrm{~N}_{5} \mathrm{P}_{2} \mathrm{~S}_{3}$ & $\mathrm{~N}_{5} \mathrm{P}_{3} \mathrm{~S}_{4}$ & $\mathrm{~N}_{5} \mathrm{P}_{4} \mathrm{~S}_{1}$ & $\mathrm{~N}_{5} \mathrm{P}_{5} \mathrm{~S}_{2}$ & \\
\hline
\end{tabular}
these are combined with the levels of factors $\mathrm{E}$ and $\mathrm{B}$. Here, levels of $(\mathrm{S})$ are in the form of a Latin square.

b) When we take the rows and columns of factor $\mathrm{N}$ and $\mathrm{P}$ of the first (original) square, and the rows of factor $\mathrm{S}$, in order of 1-2-3-4-5 from first to fifth, the arrangement follows as in order of $2-3-4-5-1$ in the second square, in 
order of 3-4-5-1-2 in the third square, in order of 4-5-1-2-3 in the fourth square and in order of 5-1-2-3-4 in the fifth square. Here, for example, the second arrangement means this: the combinations on the second row and column of the first (original) square will be on the first row and column of the second square. And when continued, the combinations on the third row and column of the first square will be on the second row and column of the second square, the combinations on the fourth row and column of the first square will be on the third row and column of the second square, the combinations on fifth row and column of the first square will be on the fourth row and column of the second square, and finally the combinations on the first row and column of the first square will be on the fifth row and column of the second square.

3. Since each level of a factor is scanned five times on a square, the individual $\mathrm{R}$ values total belonging to the factor in question in the combinations is $\mathrm{R}=(5)(0.760)=3.800$. Since there are five factors in a square, the individual $\mathrm{R}$ values total becomes

$\mathrm{R}=(5)(3.800)=19$. On the other hand, since each level of each factor is repeated 25 times in 125 combinations;

$\sum R_{E}=\sum R_{B}=\sum R_{N}=\sum R_{P}=\sum R_{S}=19$.

In addition,

$\mathrm{R}=\mathrm{D}+R_{E}+R_{B}+R_{N}+R_{P}+R_{S}$

$\mathrm{D}=\mathrm{D}_{1}+\mathrm{D}_{2}+\mathrm{D}_{3}+\mathrm{D}_{4}+\mathrm{D}_{5}$

$\mathrm{D}=\frac{\sum R-\sum R_{E}-\sum R_{B}-\sum R_{P}-\sum R_{S}}{125}=\frac{19-19-19-19-19}{125}$

Therefore, using;

$\mathrm{R}=-0.6080+R_{E}+R_{B}+R_{N}+R_{P}+R_{S}$

The final $\mathrm{R} 1$ value corresponding to the fifth combination ( $E_{1}, B_{1}, N_{1}, P_{1}, S_{1}$ ) on the first (original) square, for example, is calculated as follows;

$R_{1}=-0.6080+0.0830+0.1334+0.2811+0.1518+0.1378=0.1791$

Final $\mathrm{R}$ values belonging to the other combinations are calculated with a similar method.

For maximization, forming an original square based on a combination of maximum individual $\mathrm{R}$ values total (E5, B5, N1, P4, S5) will be enough.

The original square is shown below.

\begin{tabular}{lcccccc}
\hline & $\mathrm{B}_{1}$ & $\mathrm{~B}_{2}$ & $\mathrm{~B}_{3}$ & $\mathrm{~B}_{4}$ & $\mathrm{~B}_{5}$ & \\
\hline $\mathrm{E}_{1}$ & $\mathrm{~N}_{5} \mathrm{P}_{3} \mathrm{~S}_{5}$ & $\mathrm{~N}_{5} \mathrm{P}_{1} \mathrm{~S}_{3}$ & $\mathrm{~N}_{5} \mathrm{P}_{2} \mathrm{~S}_{4}$ & $\mathrm{~N}_{5} \mathrm{P}_{3} \mathrm{~S}_{1}$ & $\mathrm{~N}_{5} \mathrm{P}_{4} \mathrm{~S}_{1}$ & \\
$\mathrm{E}_{2}$ & $\mathrm{~N}_{4} \mathrm{P}_{5} \mathrm{~S}_{4}$ & $\mathrm{~N}_{4} \mathrm{P}_{1} \mathrm{~S}_{5}$ & $\mathrm{~N}_{4} \mathrm{P}_{2} \mathrm{~S}_{2}$ & $\mathrm{~N}_{4} \mathrm{P}_{3} \mathrm{~S}_{3}$ & $\mathrm{~N}_{4} \mathrm{P}_{4} \mathrm{~S}_{2}$ & $5-4-3-2-1$ \\
$\mathrm{E}_{3}$ & $\mathrm{~N}_{3} \mathrm{P}_{5} \mathrm{~S}_{3}$ & $\mathrm{~N}_{3} \mathrm{P}_{1} \mathrm{~S}_{1}$ & $\mathrm{~N}_{3} \mathrm{P}_{2} \mathrm{~S}_{5}$ & $\mathrm{~N}_{3} \mathrm{P}_{3} \mathrm{~S}_{2}$ & $\mathrm{~N}_{3} \mathrm{P}_{4} \mathrm{~S}_{4}$ & \\
$\mathrm{E}_{4}$ & $\mathrm{~N}_{2} \mathrm{P}_{5} \mathrm{~S}_{2}$ & $\mathrm{~N}_{2} \mathrm{P}_{1} \mathrm{~S}_{4}$ & $\mathrm{~N}_{2} \mathrm{P}_{2} \mathrm{~S}_{1}$ & $\mathrm{~N}_{2} \mathrm{P}_{3} \mathrm{~S}_{5}$ & $\mathrm{~N}_{2} \mathrm{P}_{4} \mathrm{~S}_{3}$ & \\
$\mathrm{E}_{5}$ & $\mathrm{~N}_{1} \mathrm{P}_{5} \mathrm{~S}_{1}$ & $\mathrm{~N}_{1} \mathrm{P}_{1} \mathrm{~S}_{2}$ & $\mathrm{~N}_{1} \mathrm{P}_{2} \mathrm{~S}_{3}$ & $\mathrm{~N}_{1} \mathrm{P}_{3} \mathrm{~S}_{4}$ & $\mathrm{~N}_{1} \mathrm{P}_{4} \mathrm{~S}_{5}$ & \\
\hline
\end{tabular}

\section{Research Findings}

Since the final $\mathrm{R}$ values and individual $R_{E}, R_{B}, R_{N}, R_{P}$, $R_{S}$ values are known, the (D) values can easily be calculated. For example, the $\mathrm{D}_{1}$ and $\mathrm{D}_{2}$ values belonging to $E_{1}, B_{1}, N_{1}, P_{1}, S_{1}$ and $E_{1} B_{2} N_{1} \mathrm{P}_{2} \mathrm{~S}_{2}$ combinations are calculated using the following method.

Since $\mathrm{R}=\mathrm{D}+R_{E}+R_{B}+R_{N}+R_{P}+R_{S}$ is known, the $\mathrm{R}$ values of the combinations in question can be expressed as follows.

$$
\begin{aligned}
& R_{1}=D_{1}+R_{E_{1}}+R_{B_{1}}+R_{N_{1}}+R_{P_{1}}+R_{S_{1}} \text { and } \\
& R_{2}=D_{2}+R_{E_{1}}+R_{B_{2}}+R_{N_{1}}+R_{P_{2}}+R_{S_{2}}
\end{aligned}
$$

Therefore:

$0.1791=\mathrm{D}_{1}+0.0830+0.1334+0.2811+0.1518+0.1373$

$$
\mathrm{D}_{1}=-0.6075
$$

$0.1875=\mathrm{D}_{2}+0.0830+0.1399+0.2811+0.1519+0.1396$

$$
\mathrm{D}_{2}=-0.6080
$$

Other D values are calculated using a similar method. When we take the average of calculated 125 values we find $\mathrm{D}=-0.6080$.

Maximization operation:

Therefore, the combination with the largest final $\mathrm{R}$ value should be chosen. This is found at the coordinates $(X=0.4104, R E=0.2762) ;(X=0.4076, R B=0.1886)$;

$(\mathrm{X}=0.7303, \mathrm{RN}=0.2811) ;(\mathrm{X}=0.646, \mathrm{RP}=0.1522)$;

$(\mathrm{X}=0.6831, \mathrm{Rs}=0.1968)$

Therefore;

$$
\begin{aligned}
& R_{\max }=\mathrm{D}+R_{E}+R_{B}+R_{N}+R_{P}+R_{S}= \\
& -0.6080+0.2762+0.1886+0.2811+0.1522+0.1968 \\
& =0.4869 \text { or } \\
& R_{\text {max }}=(0.4869)(1544.692)=752.110 \mathrm{~kg} / \text { decare }
\end{aligned}
$$

Here;

$$
\begin{aligned}
& \sqrt{\Sigma y^{2}}=1544.692 \\
& \mathrm{E}=(0.4104)(292.4038)=120 \text { days }\left(\text { May } 1^{\mathrm{st}}\right) \\
& \mathrm{B}=(0.4976)(13521.166)=1511 \text { pieces }(24 \mathrm{~cm} \times 77 \mathrm{~cm}) \\
& \mathrm{N}=(7303)(21.9086)=16 \mathrm{~kg} / \text { decare } \\
& \mathrm{P}=(0.6460)(13.4164)=8.667 \mathrm{~kg} / \text { decare } \\
& \mathrm{S}=(0.6831)(512.375)=350 \text { Tonnes } / \text { decare }
\end{aligned}
$$

\section{Argument and Conclusion}

Based on these data, the following propositions can be made

1. The variables used in individual trials should be standardized.

2. Regression equations should be generated using the numerical data obtained from the individual trials.

3. The calculation of a common level number and individual $\mathrm{R}$ values total for the individual trials should be based on the individual trial or trials with the smallest level number and individual $\mathrm{R}$ values total. Here, the most recurring level number should be accepted as the common level number, if any, and common individual $\mathrm{R}$ values total should be calculated based on this common level number. If 
there is no recurrent level number, the largest level number should be accepted as the common level number and the maximum individual $\mathrm{R}$ values total calculated based on this common level number should be accepted as the common individual $\mathrm{R}$ value.

4. Square Formation Technique:

When the number of variables is maximum:

Whether the number of variables is odd or even, two variables should always be placed in the topmost rows outside the squares. While the order of levels of one variable is changed on each square, the other one should stay fixed. There should not be any relation between displacement of the variable level in question placed outside square and on top row and the displacement of the variable levels inside the square. On condition of covering all squares with a fixed level variable on a column in the squares, the same variable should form a Greco-Latin $n$ square. Variables in numbers equals to the level number should always be placed on the leftmost columns outside the squares. Each fixed level of one of these should be placed vertically on all squares. The levels of one of the remaining variables shall be arranged vertically on ascending order of levels, and this order should stay the same on all squares. The other variables on the left column in question should form a Greco-Latin square, on condition of covering all squares with the variable in the squares whose each level is horizontally fixed. Squares should include a variable row whose each level is horizontally fixed, as in 1-2-3-4-5 arrangement, and a variable column whose each level is vertically fixed, and elements of a square formed by Latin squares with different arrangements equal in number to the level number.

The method for forming the other squares after the first square is formed is explained under Item (4.2.b). Where the level number is 2 , maximum two squares sized $2 \times 2$ with 7 variables and minimum one square sized $2 \times 2$ with 2 variables can be formed; where the level number is 3 , maximum three squares sized $3 \times 3$ with 10 variables and minimum one square of same size with 3 variables can be formed; where level number is 4 , maximum four squares sized $4 \times 4$ with 12 variables and minimum one square of same size with 4 variables can be formed; and where the level number is 5 , maximum five squares sized $5 \times 5$ with 14 variables and minimum one square of same size with 5 variables can be formed. As an example, a 3 level plan is shown below.

\begin{tabular}{|c|c|c|c|c|c|c|c|}
\hline & & \multicolumn{2}{|c|}{$\mathrm{D}_{1} \mathrm{E}_{1}$} & \multicolumn{2}{|c|}{$\mathrm{D}_{2} \mathrm{E}_{2}$} & \multicolumn{2}{|c|}{$\mathrm{D}_{3} \mathrm{E}_{3}$} \\
\hline \multicolumn{2}{|c|}{$\mathrm{C}_{1} \mathrm{~A}_{1} \mathrm{~B}_{1}$} & \multicolumn{2}{|c|}{$\mathrm{F}_{1} \mathrm{G}_{1} \mathrm{H}_{1} \mathrm{~K}_{1} \mathrm{M}_{1}$} & \multicolumn{2}{|c|}{$\mathrm{F}_{1} \mathrm{G}_{2} \mathrm{H}_{2} \mathrm{~K}_{3} \mathrm{M}_{2}$} & \multicolumn{2}{|c|}{$\mathrm{F}_{1} \mathrm{G}_{3} \mathrm{H}_{3} \mathrm{~K}_{2} \mathrm{M}_{3}$} \\
\hline \multicolumn{2}{|c|}{$\mathrm{C}_{1} \mathrm{~A}_{2} \mathrm{~B}_{2}$} & \multicolumn{2}{|c|}{$\mathrm{F}_{2} \mathrm{GlH}_{2} \mathrm{~K}_{2} \mathrm{M}_{2}$} & \multicolumn{2}{|c|}{$\mathrm{F}_{2} \mathrm{G}_{2} \mathrm{H}_{3} \mathrm{~K}_{1} \mathrm{M}_{3}$} & \multicolumn{2}{|c|}{$\mathrm{F}_{2} \mathrm{G}_{3} \mathrm{H}_{1} \mathrm{~K}_{3} \mathrm{M}_{1}$} \\
\hline \multicolumn{2}{|c|}{$\mathrm{C}_{1} \mathrm{~A}_{3} \mathrm{~B}_{3}$} & \multicolumn{2}{|c|}{$\mathrm{F}_{3} \mathrm{GiH}_{3} \mathrm{~K}_{3} \mathrm{M}_{3}$} & \multicolumn{2}{|c|}{$\mathrm{F}_{3} \mathrm{G}_{2} \mathrm{H}_{1} \mathrm{~K}_{2} \mathrm{M}_{1}$} & \multicolumn{2}{|c|}{$\mathrm{F}_{3} \mathrm{G}_{3} \mathrm{H}_{2} \mathrm{~K}_{1} \mathrm{M}_{2}$} \\
\hline & $\mathrm{D}_{3} \mathrm{E}_{1}$ & $\mathrm{D}_{1} \mathrm{E}_{2}$ & $\mathrm{D}_{2} \mathrm{E}_{3}$ & & $\mathrm{D}_{2} \mathrm{E}_{1}$ & $\mathrm{D}_{3} \mathrm{E}_{2}$ & $\mathrm{D}_{1} \mathrm{E}_{3}$ \\
\hline $\begin{array}{c}\mathrm{C}_{2} \mathrm{~A}_{3} \\
\mathrm{~B}_{1}\end{array}$ & $\begin{array}{c}\mathrm{F}_{2} \mathrm{G}_{2} \\
\mathrm{H}_{2} \\
\mathrm{~K}_{2} \mathrm{M}_{1}\end{array}$ & $\begin{array}{c}\mathrm{F}_{2} \mathrm{G}_{3} \\
\mathrm{H} 3 \\
\mathrm{~K}_{1} \mathrm{M}_{2}\end{array}$ & $\begin{array}{c}\mathrm{F}_{2} \mathrm{G}_{1} \\
\mathrm{H}_{1} \\
\mathrm{~K}_{3} \mathrm{M}_{3}\end{array}$ & $\begin{array}{c}\mathrm{C}_{3} \mathrm{~A}_{2} \\
\mathrm{~B}_{1}\end{array}$ & $\begin{array}{c}\mathrm{F}_{3} \mathrm{G}_{3} \\
\mathrm{H}_{3} \\
\mathrm{~K}_{3} \mathrm{M}_{1}\end{array}$ & $\begin{array}{c}\mathrm{F}_{3} \mathrm{G}_{1} \\
\mathrm{H}_{1} \\
\mathrm{~K}_{2} \mathrm{M}_{2}\end{array}$ & $\begin{array}{c}\mathrm{F}_{3} \mathrm{G}_{2} \\
\mathrm{H}_{2} \\
\mathrm{~K}_{1} \mathrm{M}_{3}\end{array}$ \\
\hline $\begin{array}{c}\mathrm{C}_{2} \mathrm{~A}_{1} \\
\mathrm{~B}_{2}\end{array}$ & $\begin{array}{c}\mathrm{F}_{3} \mathrm{G}_{2} \\
\mathrm{H}_{3} \\
\mathrm{~K}_{3} \mathrm{M}_{2}\end{array}$ & $\begin{array}{c}\mathrm{F}_{3} \mathrm{G}_{3} \\
\mathrm{H}_{1} \\
\mathrm{~K}_{2} \mathrm{M}_{3}\end{array}$ & $\begin{array}{c}\mathrm{F}_{3} \mathrm{G}_{1} \\
\mathrm{H}_{2} \\
\mathrm{~K}_{1} \mathrm{M}_{1}\end{array}$ & $\begin{array}{c}\mathrm{C}_{3} \mathrm{~A}_{3} \\
\mathrm{~B}_{2}\end{array}$ & $\begin{array}{c}\mathrm{F}_{1} \mathrm{G}_{3} \\
\mathrm{H}_{1} \\
\mathrm{~K}_{1} \mathrm{M}_{2}\end{array}$ & $\begin{array}{c}\mathrm{F}_{1} \mathrm{G}_{1} \\
\mathrm{H}_{2} \\
\mathrm{~K}_{3} \mathrm{M}_{3}\end{array}$ & $\begin{array}{c}\mathrm{F}_{1} \mathrm{G}_{2} \\
\mathrm{H}_{3} \\
\mathrm{~K}_{2} \mathrm{M}_{1}\end{array}$ \\
\hline $\begin{array}{c}\mathrm{C}_{2} \mathrm{~A}_{2} \\
\mathrm{~B}_{3}\end{array}$ & $\begin{array}{c}\mathrm{F}_{1} \mathrm{G}_{2} \\
\mathrm{H}_{1} \\
\mathrm{~K}_{1} \mathrm{M}_{3} \\
\end{array}$ & $\begin{array}{c}\mathrm{F}_{1} \mathrm{G}_{3} \\
\mathrm{H}_{2} \\
\mathrm{~K}_{3} \mathrm{M}_{1}\end{array}$ & $\begin{array}{c}\mathrm{F}_{1} \mathrm{G}_{1} \\
\mathrm{H}_{3} \\
\mathrm{~K}_{2} \mathrm{M}_{2}\end{array}$ & $\begin{array}{c}\mathrm{C}_{3} \mathrm{~A}_{1} \\
\mathrm{~B}_{3}\end{array}$ & $\begin{array}{c}\mathrm{F}_{2} \mathrm{G}_{3} \\
\mathrm{H}_{2} \\
\mathrm{~K}_{2} \mathrm{M}_{3} \\
\end{array}$ & $\begin{array}{c}\mathrm{F}_{2} \mathrm{G}_{1} \\
\mathrm{H}_{3} \\
\mathrm{~K}_{1} \mathrm{M}_{1} \\
\end{array}$ & $\begin{array}{c}\mathrm{F}_{2} \mathrm{G}_{2} \\
\mathrm{H}_{1} \\
\mathrm{~K}_{3} \mathrm{M}_{2}\end{array}$ \\
\hline
\end{tabular}

5. In $\Delta_{\mathrm{y} \text { operations }} \Delta_{\mathrm{X}}$ should be accepted as $\Delta_{\mathrm{X}}=$ 0.01 .

6. In case the model is a product (interactive) type as in $\mathrm{R}=f_{1}(\mathrm{X}) . f_{2}(\mathrm{Y}) . f_{3}(\mathrm{Z})$, same operations should be applied after taking logarithm of both sides.

\section{References}

[1] Ackermann,W,1955. Einführung in der wahrscheinlichketts Rechnung,S.Hirsel Verkag.

[2] Gnedonko, B.G.1955. Elamentere Einführung in Die wahrscheinlichkeits Rechnung.

[3] Hald, A. 1952. Statistical Theory With Engineering Applications, 507-510 University of Copenhagen, John Wiley and Sons, Inc, New York, "London, Sydney.

[4] Hans-Jochen Bartsch. 1969. Mathematische Formeln Veb. Fachbuchverlag, Leibzig.

[5] Schenck, Hilbert, Jr. 1961. Theories of Engineering Experimentation,103-115 Department of Mechanical Engineering, Clarkson College of Technology, Mc Graw-Hill Book Company, New York, Toronto, London

[6] Babur, Yunus, 1991. Muhendisler Icın Matematik, 191-260 Ege Universitesi Su Urunleri Yuksek Okulu, No:24., Bornova, Izmir, Turkiye. 